\title{
Integration of Online Labs into Educational Systems
}

\author{
http://dx.doi.org/10.3991/ijoe.v11i6.5145 \\ M. Ožvoldová ${ }^{1}$ and. P Ondrůšek ${ }^{2}$ \\ ${ }^{1}$ Trnava University in Trnava, Faculty of Education, Trnava, Slovak Republic \\ 2 Tomas Bata University in Zlín, Zlín, Czech Republic
}

\begin{abstract}
Online STEM (Science, Technology, Engineering and Mathematics) education needs online labs - the same way as classical education at schools need access to real laboratories, because various technical skills and prowesses can be effectively achieved only by putting theory into practice. There are series of open online labs available today, especially thanks to fast ICT (Information and Communications Technology) growth and innovations provided by many universities. Nevertheless integration of online labs into education systems occurs sporadically. Article aims to map the current integration options, give some existing examples and analyze how it would be possible to start the integration of online labs on a global scale.
\end{abstract}

Index Terms-Online laboratories, remote experiment, GoLab, RemLabNet, MOOC

\section{INTRODUCTION}

The reason for the need of laboratories in education is primarily the need of activity of students themselves. They are directly exposed to the researched phenomenon in a lab, which leads to self-exploration, speculation over the problems and finding independent solutions to emerging problems. Secondly, the strong experience of laboratory work helps many students to permanently memorize studied issues, especially those whom by very nature does not suit the classic structure of education (passive lectures and study texts). During the laboratory session a greater number of distinct intelligences are activated to students [1], in particular kinesthetic, interpersonal and verbal (when more students are cooperating), which leads to overall greater brain involvement.

INTe-L (Integrated e-Learning [2]) is an example of reform approach to teaching physics in particular, which puts students in the position of researcher in the first place. The teacher does not drown students in pile of organized facts in this teaching strategy but provides them with only the most necessary resources, then he/she only serves as a mentor during their independent research. This experiment driven methodology is proving successful from a long-term point of view while being more enjoyable for students, moreover $[3,4,5]$.

The rapid development and spread of the World Wide Web carries the development of learning technologies naturally with it, formerly in the form of audio/video recordings, LMS (Learning Management System) / LCMS (Learning Content Management System) like MOODLE [6], or in the form of MOOCs (Massive Open Online Course, see [7]), which are currently experiencing their boom (see number of courses currently available e.g. on
[8]). The technological core of the educational system is primarily based on data model in a relational database management system, furthermore on file storage (with educational media) and finally on an application framework. Because of using these standardized and easily hosted IT instruments, it was relatively easy to develop these systems as web applications from the very beginning and that's why they have been deployed on the Internet massively.

In contrast, online laboratories, particularly real remote experiments (REs) require technologically demanding resources, particularly specialized hardware (e.g. A/D converters, sensors, motors, cameras), software solution with a relatively robust architecture and high-quality Internet connection (usually with real-time response). Due to absence of unified architecture every experimenter or development team was forced to choose custom platform for building REs that suited him best.

The technological barriers have been broken up much later, which may explain the belated emergence of online labs for public education. Virtualization of laboratories is therefore relatively young discipline, yet it is already available to the general public and provide a wide range of quality solutions (see e.g. [9]). Due to its technological differences, remote labs usually arose as separate projects, but in the future we can expect their integration into educational systems so as to provide students with a comprehensive and profound learning experience.

\section{CONCEPT OF INTEGRATION}

Online labs can be divided into virtual labs, working as a computer simulation of the studied phenomenon, and remote labs that are real, and the user only controls them remotely. Let's briefly analyze the integration quality parameters.

From the student perspective, the laboratory integration into educational system will be high quality if it is imperceptible - seamless. For example when student encounters an integrated online laboratory while browsing courseware, he should not get the feeling of fundamentally different technology, in order to focus his/her attention on learning itself. The quality of integration can be evaluated according to various criteria, such as by visual aspects, binding strength or support of lab session bookings/sharing.

\section{A. Visual aspects}

The lowest level of lab visual integration is using simple hyperlink within the educational system, which for example opens the lab on an external website in a new 
browser tab. This behavior usually means for user a disruption of impression integrity and can therefore be considered as a little quality integration instrument.

Another option is to insert a laboratory web application into the graphical layout of the educational system, using appropriate html element (e.g. iframe, object, applet or embed). This method is less noticeable for users and easily implemented by developers thanks to its modularity, which makes this option general popular and high quality. The disadvantage of this solution is the fixed height of the inserted element and this problem should be then resolved within the graphical layout satisfactorily.

In addition, there exists alternative method of integration, namely direct insertion of HTML code that was generated by the lab application into the web pages of the educational system. Using this variant, there is no problem with the fixed height of the inserted element - it can be a visually perfect integration solution for users. On the other hand, there is a risk of html code conflict of both pages and the need to integrate complex CSS styles and JavaScript, which can cause major problems for developers in the implementation. Perhaps that's why this alternative became little useful and sought after in practice.

\section{B. Binding strength}

Another quality aspect of integration is the interaction ability of the educational system with online labs. For instance an educational system can send the unique identification of currently logged in user to online lab, then the laboratory can somehow deal with the identity information (e.g. grant access to user's historically measured values).

Next case of communication may be the situation where the students and teachers are organized into virtual classes, so they can discuss the topic. In this case, it may be desirable to pass information about membership in the virtual classroom to integrated laboratory, so that all class members can access the ongoing lab session simultaneously while preventing access to other users.

Another issue that has to be solved is to deal with competing request of users trying to access one lab at the same time. The solution is usually found by introducing some form of reservation, either with waiting in queue for the lab to be released or with fixed reservations on the calendar. Booking functionality may be provided by online laboratory itself, or it can be implemented by the educational system through well specified interface.

Remote laboratory can support its management by periodically sending its status to remote laboratory management system or to educational system itself. Thanks to this functionality the lab administrator can rapidly make the faulty lab available again, thus preventing user disappointments.

Therefore the strength of integration binding may be weak, when both lab and educational system does not interact between themselves at all, or it can reach different levels of strength according to a variety of functions in their communication interface.

\section{Project EXAMPLeS}

Efforts to integrate online labs to the public education is evident from a number of historically more or less successful projects, let us present two examples.

\section{A. ISES \& RemLabNet}

ISES (Internet School Experimental System [10, 11, 12]) is a comprehensive set of hardware and software tools for creating remote laboratories. Many remote experiments were built using ISES, part of them became open through remote laboratory management system RemLabNet $([13,14])$. Fig. 1 presents one of the remote
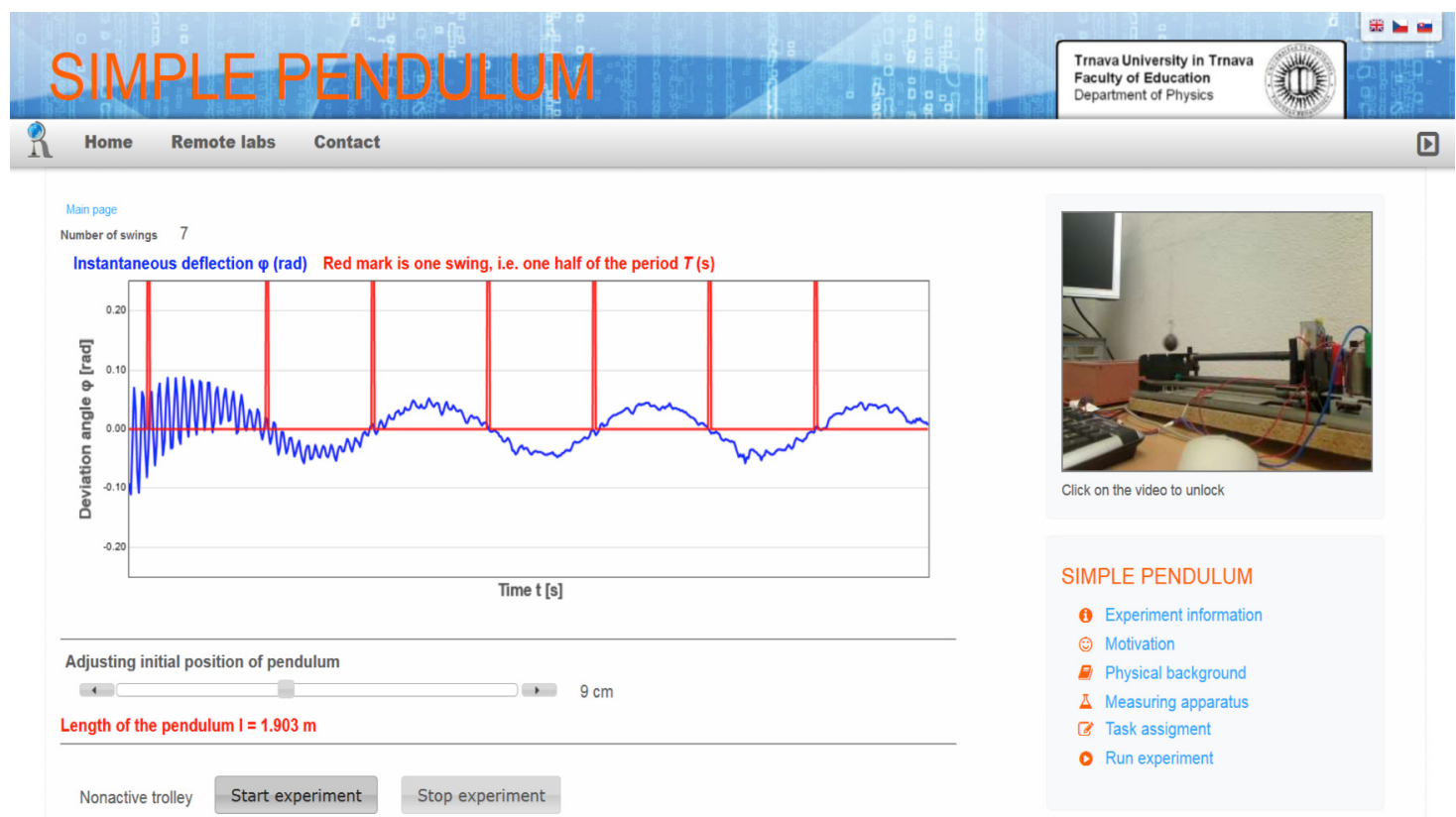

Figure 1. Example of remote laboratory "Simple Pendulum"

(ISES \& RemLabNet, screenshot was made from RemLabNet site [14]) 
PAPER

experiment, "Simple pendulum", from RemLabNet. The system includes a simple gallery of laboratories, each laboratory is complemented by metainformation describing the basic features of the experiment, motivation, theoretical foundation, description of the apparatus and assignment for students.

Laboratory control is managed by the reservation system, all waiting students can only watch ongoing session of the user with full access granted. Besides standard expected modules (e.g. webcam broadcasting, visualization of measurement data in a graph, feedback to administrators) RemLabNet system also offers a range of advanced functionalities, such as lab self-diagnostics, measurement data warehouse (allowing further analysis) and data exporting.

The solution can be considered as integration of online lab into external system (e.g. in Fig. 1), in this case the laboratory is inserted into the master system as an embedded html element (iframe). Because there is a semaphore, graphically indicating actual experiment availability in the gallery and the lab supports reservations, this binding has medium strength.

\section{B. LabVIEW \& MOODLE plugin}

There are several plugins for MOODLE enabling integration of remote experiments. For instance, two remote experiments were established (as seen in [15]) using a MOODLE plugin for remote lab reservation [16]. These labs were built on custom made hardware, using LabVIEW [17] and MATLAB [18] for automation control and data presentation.

A more recent example of cooperation between specialized hardware, laboratory system LabVIEW, Easy Java Simulations framework (EJS, see [19]) and the MOODLE plugin is remote experiment described in the article [20]. This solution uses EJSApp plugin [21] for integration into MOODLE. Plugin offers the functionality of the reservations and is able to organize shared sessions within the virtual classes, so the whole integration have strong binding. EJSApp has its own operational application, namely within UNILabs portal [22], which contains a number of online laboratories that are enriched by documentation and by instructions for students (e.g. in Fig. 2).

\section{INTEGRATION PROCESS}

Since 2012 there is a rapid rise of MOOC courses noticeable in the sphere of public education. These courses currently represent one of the most effective and sought-after learning channels, for example there are hundreds of free STEM courses available on EdX [23] and Coursera [24] platforms, including physics, chemistry and mathematics materials. A brief survey of physics courses available on EdX and Coursera platforms indicates that courses includes online laboratories very rarely (an exception is shown in Fig. 3), in spite of the fact that the demand for online labs is one of the highest particularly in the area of physics. It can be concluded that the integration of online laboratories into public educational systems is still immature and does not take place too much yet. Some courses (e.g. [25]) circumvent this problem by leading their students to install an additional software on their client stations, which actually creates a set of home virtual laboratories. Other courses (e.g. [26]) have even prepared cheap laboratory kits in cooperation with electronics manufacturers. Students are obliged to purchase these devices for successful completion of the course while creating their real home labs.

In this situation, the question arises how to start the process of online labs integration, which are already available to the public at a wide range (see e.g. [9]). Another question can bring us the answers, namely what do the creators of courses need to start integrating online labs into them. If the author wishes to use an online laboratory in some course section, he needs to know about existence of an appropriate laboratory at the first place.

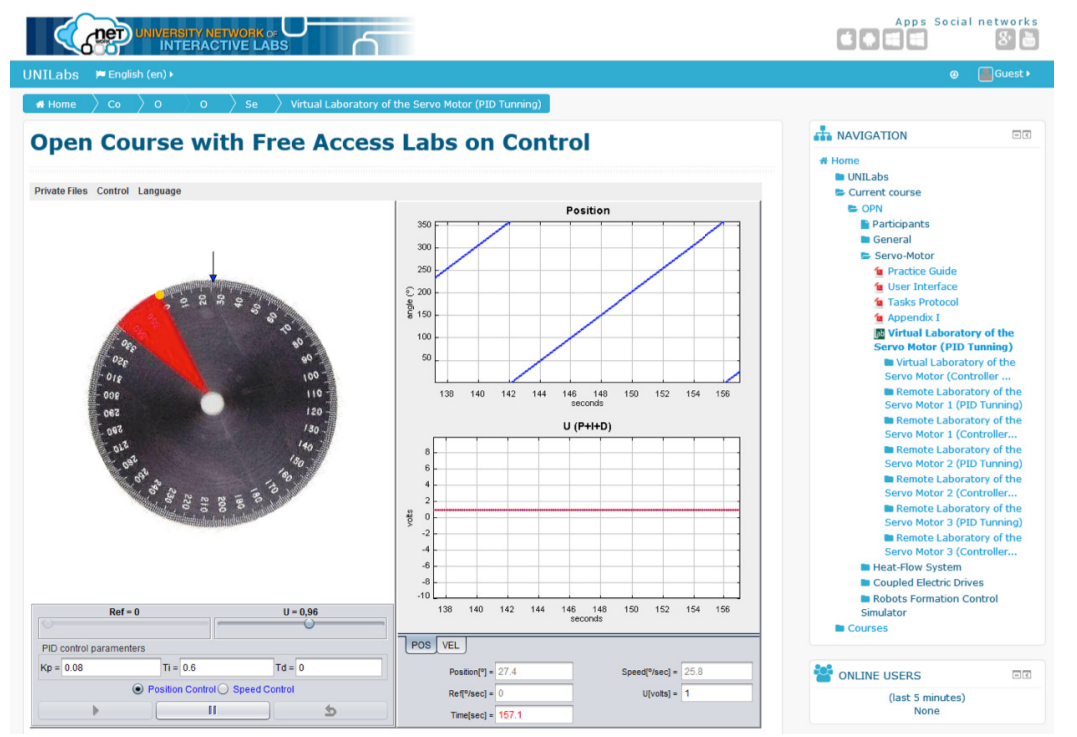

Figure 2. Demonstration of "Virtual Laboratory of the Servo Mptor"

(UNILabs, screenshot was made 6 physies courses on 4 Coursera and 3 physics courses on Coursera were examined (on September 3, 2015) 
PAPER

INTEGRATION OF ONLINE LABS INTO EDUCATIONAL SYSTEMS

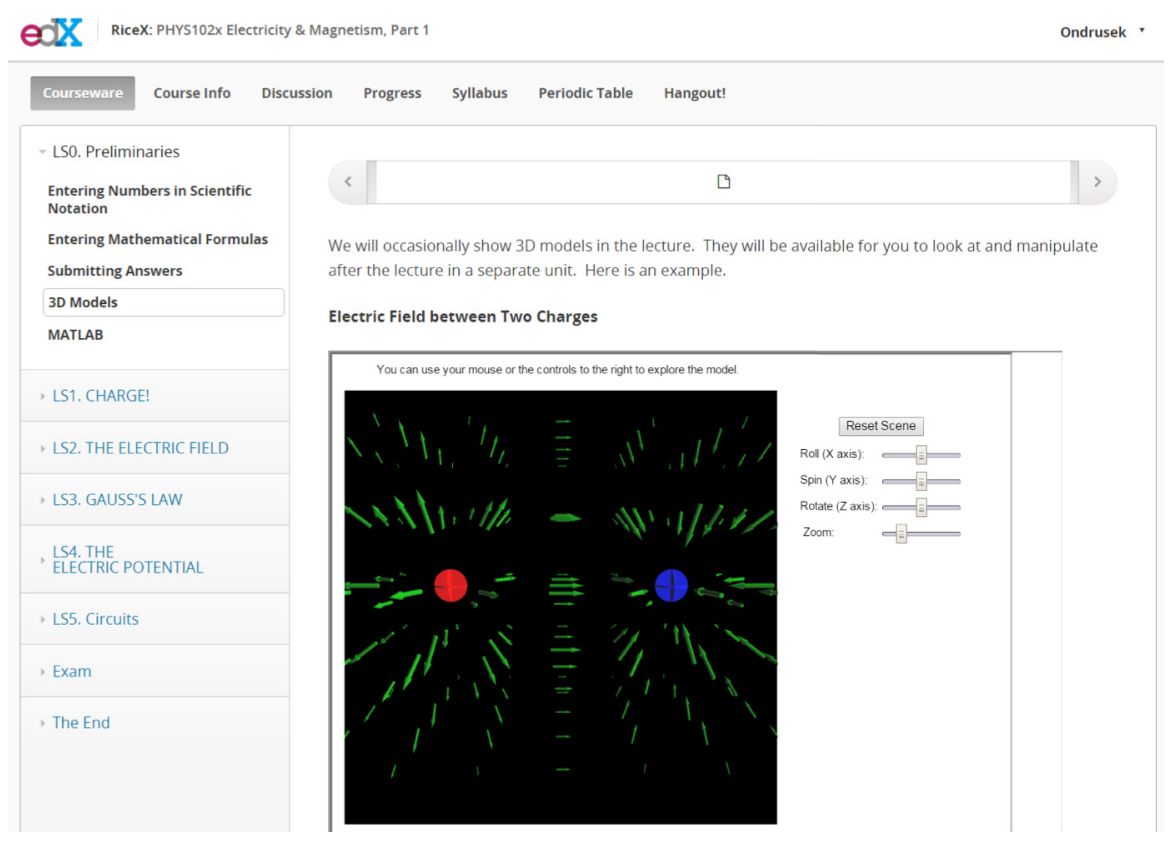

Figure 3. Demonstration of virtual lab integrated into MOOC

(Screenshot was made from EdX platform [23])

It follows the first requirement, namely the request for a centralized gallery of available laboratories, ideally with the option to search by multiple criteria (e.g. by subject domains, by complexity, by supported language). Then, when the course creator identifies an appropriate laboratory in the gallery, he needs a very simple tool (shielded from the technical implementation details) to insert the lab into the course. This integration tool represents the second requirement, which must be met in order to online laboratories start to be used in educational systems intensely and worldwide. There are two existing specifications (SCORM [27] and IMS LTI [28]), which have become more or less accepted standards for integration of external elements into courseware. It would be advantageous to use these specifications while preparing lab integration instrument. Efforts to integrate online labs to the public education is evident from a number of historically more or less successful projects, let us present two examples.

\section{A. Go-Lab project}

Meanwhile, online laboratories are created and maintained in academic sphere in many cases, and so a number of high quality, but orphaned projects exists. Laboratory projects are fragmented and have limited opportunities of promotion, which is inconsistent with the first requirement of courses authors (a need of comprehensive lab gallery). Most of the academic projects use their own original solution architecture, which causes a need to create custom integration tools complemented with sufficient documentation. Subsequently, various integration tools tend to be confusing to end users (the creators of courses) and therefore unavailable for real mass deployment. That's why the second requirement of the authors is also not met.

Since November 1, 2012 (see [29]) European project Go-Lab [30, 31] has been started, which should bring a solution to both problems just described. The main objectives of the project include creating an international federation of online lab providers, encouraging cooperation between these providers, creating an online lab gallery available to public and providing a single integration and communication interface. Gallery of laboratories is published on the website [9] and it already contains 125 virtual and 30 remote laboratories (reported on September 2, 2015), while this number is still growing.

Go-Lab integration interface is called Smart Gateway (or alternatively "gateway4labs", see [32, 33]), it aims to gain external systems access to labs from the gallery and to simplify adding new laboratories into the gallery on the other hand. Even though the Smart Gateway development project is still young and ongoing, it already includes integration plugins for LMS MOODLE [6] and CMS Joomla [34], as illustrated on the architecture diagram in Fig. 4. Because all the source code of gateway4labs is available open source and there is an underlying documentation, it is possible to create similar plugins for MOOC platforms like EdX and Coursera as well.

\section{B. Graasp platform}

The gallery of online laboratories [9] is closely connected to Graasp platform, which was created as part of the Go-Lab project. Graasp was designed for publishing learning materials, in close conjunction with the online laboratories. An intuitive editing environment is offered to teachers, so that the lab itself can be easily supplemented by custom learning materials, which should inspire the student during the investigation of studied phenomenon. User-friendliness is achieved thanks to the generated template, which leads the author to methodological structure of edited content. The platform allows you to insert a variety of related applications (e.g. calculator, hypothesis designer, graph designer, periodic table), it is 


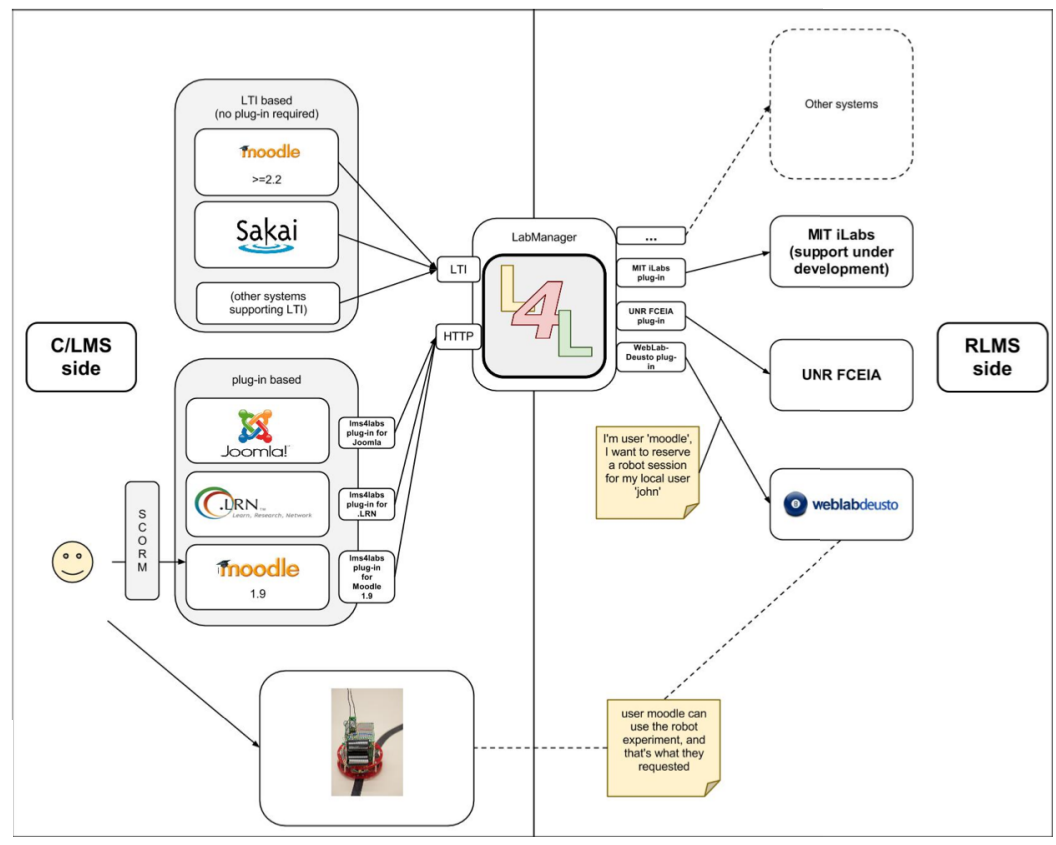

Figure 4. Smart Gateway architecture (retrieved from [33])

well documented and there is a growing community of authors established as well.

On the other hand, Graasp platform is still immature if we treat it as complete education system as compared with wide spread systems (e.g. EdX, Coursera, MOODLE). For instance, the provided content is not much scalable, there are only two localizations supported now (English and French) and there are some common LMS elements missing (e.g. rich student database, quizzes, questionnaires, tasks with evaluation, badges). The platform is still under constant development, therefore we can expect it to gain further improvements that can get it rid of some shortcomings.

\section{CONCLUSION}

In order to start the integration of online laboratories on a large-scale, it is necessary to establish a central gallery of available laboratories and prepare tools for fast and easy lab integration with maximum user-friendliness. As discussed above, complex Go-Lab project is trying to solve both problems (likewise tried projects Labshare [35] and iLabCentral [36] formerly) by building a global federation of lab providers, by publishing gallery of laboratories on the public website and by development of versatile tools for external systems integration. Graasp platform is probably the most advanced example of online lab integration at the moment, which is already well usable online education supplement today.

Go-Lab project, among other things, builds open source interface Smart Gateway, which has a chance to become the online lab integration standard, especially thanks to the fact that project Go-Lab has received great support of many partners, e.g. Consortium of three Universities: Trnava University in Trnava, Slovakia, Tomas Bata University in Zlín and Charles University in Prague, Czech Republic, with more than thirty remote real science experiments accessible also via the RemLabNet [14]. We can expect involving further online lab providers into Go-
Lab consortium and promoting new integrated educational materials to large-scale education.

The next breakthrough in online labs usability is likely coming after the Smart Gateway interconnection with most frequently used educational platforms (e.g. EdX, Coursera), when the authors of the courses will be equipped with simple tool for integrating online labs, while shielded from the technical details of integration.

Go-Lab project is to be officially finished on the October 31, 2016 (see [29]), we should hope that its activities will not perish successively (as many former projects), but it will receive strong support constantly and continue to implement its objectives.

\section{ACKNOWLEDGMENTS}

The authors would like to thank the Grant Agency of the Ministry of Education of the Slovak Republic.

\section{REFERENCES}

[1] Gardner, Howard: Frames of Mind, The Theory of Multiple Intelligences. Basic Books, 1983, ISBN 0133306143.

[2] F. Schauer, M. Ožvoldová, F. Lustig, Integrated e-Learning - New Strategy of Cognition of Real World in Teaching Physics. Innovations 2009, World Innovations in Engineering Education and Research, iNEER / ed. W. Aung, et al., 2009, pp. 119-135, ISBN 978-0-9741252-9-9.

[3] F. Schauer, M. Ožvoldová, L. Tkáč, INTe-L: wide open door for education by remote and virtual experiments exemplified on electricity, magnetism and electromagnetism. University of Deusto, Bilbao, Spain, 2013, pp. 205-251, ISBN 978-84-1575916-4.

[4] M. Ožvoldová, F. Schauer, Remote Experiments in Freshman Engineering Education by Integrated e-Learning. Internet accessible remote laboratories: scalable e-Learning tools for engineering and science disciplines / Abul K. M. Azad; Michael E. Auer; V. Judson Harward, Hershey, USA: IGI Global, 2011, ISBN pp. 60-83, 978-1-61350-187-0.

[5] M. Ožvoldová, F. Schauer, Remote Laboratories in research-based education of real world. Frankfurt am Main: Peter Lang, 2015, in print, ISBN 978-80-224-1435-7. 
[6] MOODLE course management system, Available: https://moodle.org/ (last accessed on September 30, 2015).

[7] P. Adamopoulos, What Makes a Great MOOC? An Interdisciplinary Analysis of Student Retention in Online Courses, Proceedings of the 34th International Conference on Information Systems, ICIS Milan, Italy, 2013, Available: http://pages.stern.nyu.edu/ padamopo/What $\% 20$ makes $\% 20 \mathrm{a} \% 20 \mathrm{~g}$ reat\%20MOOC.pdf, (last accessed on September 30, 2015).

[8] Directory of Massive Open Online Courses, Available: https://www.mooc-list.com/ (last accessed on September 30, 2015).

[9] Go-Lab Portal, Available: http://www.golabz.eu/ (last accessed on September 30, 2015).

[10] Internet School Experimental System ISES, Available: http://www.ises.info/ (last accessed on September 30, 2015).

[11] M. Krbeček, F. Schauer, F. Lustig, Easy Remote ISES Development Environment Remote Experiments. Innovations 2013, World Innovations in Engineering Education and Research, pp. 81-100, ISBN 978-0-9818868-4-8.

[12] F. Schauer, F. Lustig, M. Ožvoldová, An Internet Natural Science Remote e-Labortory (INRe-L) for Remote Experiments. Innovations 2011, World Innovations in Engineering Education and Research, iNEER / ed. W. Aung, et al., pp. 51-68.

[13] F. Schauer, M. Krbeček, P. Beňo, M. Gerža, L. Pálka, P. Spiláková, REMLABNET - Open remote laboratory management system for e-experiments, Proceedings of 2014 11th International Conference on Remote Engineering and Virtual Instrumentation, REV 2014, pp. 268-273.

[14] The Remote Laboratory Management System, Available: http://www.remlabnet.eu/ (last accessed on September 30, 2015).

[15] S. Uran, D. Hercog, K. Jezernik, Remote Control Laboratory with Moodle Booking System. Industrial Electronics, 2007, ISIE 2007, pp. 2978-2983.

[16] J. M. Martins Ferreira; A. M. Cardoso: A Moodle extension to book online labs, International association of Online Engineering, 2005, Available: http://www.arteclab.unibremen.de/Projects/marvel/fileadmin/templates/MARVEL/docum ents/2005-06-rev05-FEUP.pdf

[17] LabVIEW System Design Software, Available: http://www.ni.com/labview/ (last accessed on September 30, 2015).

[18] MATLAB,

Available: http://www.mathworks.com/products/matlab (last accessed on September 30, 2015).

[19] F. Esquembre, Easy Java/Javascript Simulations, Available: http://www.um.es/fem/EjsWiki (last accessed on September 30, 2015).

[20] M. Guinaldo, L.D.L. Torre; R. Heradio, S. Dormido, A Virtual and Remote Control Laboratory in Moodle: The Ball and Beam System. Proceedings of ACE, 2013, pp.72-77.

[21] MOODLE EJSApp plugin, Available: https://moodle.org/plugins/view/modejsapp (last accessed on September 30, 2015).

[22] University Networks of Interactive Labs, Available: http://unilabs.dia.uned.es/ (last accessed on September 30, 2015).
[23] EdX, Available: https://www.edx.org/ (last accessed on September 30, 2015)

[24] Coursera, Available: https://www.coursera.org/ (last accessed on September 30, 2015).

[25] Coursera, Introductory Physics I with Laboratory, Available: https://www.coursera.org/course/phys1 (last accessed on September 30, 2015).

[26] Coursera, Fundamentals of Electrical Engineering Laboratory, Available: https://www.coursera.org/course/eefunlab (last accessed on September 30, 2015).

[27] Sharable Content Object Reference Model, Available http://www.adlnet.org/scorm (last accessed on September 30, 2015).

[28] IMS Learning Tools Interoperability, http://www.imsglobal.org/activity/learning-tools-interoperability (last accessed on September 30, 2015).

[29] CORDIS (Community Research and Development Information Service): Go-Lab project details. Last update 6, 10, 2014, http://cordis.europa.eu/project/rcn/105919 en.html (last accessed on September 30, 2015).

[30] Global Online Science Labs for Inquiry Learning at School, http://www.go-lab-project.eu// (last accessed on September 30, 2015).

[31] T. De Jong, S. Sotiriou, D. Gillet, Innovations in STEM education The Go-Lab federation of online labs. Publication Publisher: Smart Learning Environments, 1, 3, 2014 http://dx.doi.org/10.1186/s40561-014-0003-6

[32] S. Govaerts: Specifications of the Lab Owner and Cloud Services (initial) - M21 revision, 2014, Available: http://www.go-labproject.eu/deliverables (last accessed on September 30, 2015).

[33] Gateway4labs documentation, release $0.1,2014$ http://gateway4labs.readthedocs.org/, Available: (last accessed on September 30, 2015).

[34] Joomla, Available: http://www.joomla.org/ (last accessed on September 30, 2015)

[35] Labshare, The Labshare Institute, Available: http://www.labshare. edu.au/ (last accessed on September 30, 2015).

[36] iLabCentral, Available: http://ilabcentral.org/ (last accessed on September 30, 2015).

\section{AUTHORS}

Miroslava Ožvoldová is with Trnava University in Trnava, Faculty of Education, Department of Physics, Priemyselná 4, 91701 Trnava, Slovak Republic.

Petr Ondrůšek is with Tomas Bata University in Zlín, Faculty of Applied Informatics, Nad Stráněmi 4511, 760 05 Zlín, Czech.

This work has been supported by the Grant Agency of the Ministry of Education of the Slovak Republic - KEGA No. 020TTU-4/2013 "Accreditation of personalized ICT natural sciences teacher's education centre". Submitted, 14 October 2015. Published as resubmitted by the authors on 2 November 2015 . 